\title{
AVALIAÇÃO EXTERNA DAS INSTITUIÇÕES DE EDUCAÇÃO SUPERIOR: UM ESTUDO COMPARADO ENTRE BRASIL E CABO VERDE ${ }^{1}$
}

\author{
EXTERNAL EVALUATION OF HIGHER EDUCATION
}

INSTITUTIONS: A COMPARATIVE STUDY BETWEEN BRAZIL

AND CAPE VERDE

\section{EVALUACIÓN EXTERNA DE LAS INSTITUCIONES DE EDUCACIÓN SUPERIOR: UN ESTUDIO COMPARADO ENTRE BRASIL Y CABO VERDE}

\author{
Gionara Tauchen ${ }^{2}$ \\ Universidade Federal do Rio Grande (FURG), Docente dos Programas de Pós-graduação em \\ Educação e Educação em Ciências: Química da Vida e Saúde

\section{João Felisberto Fernandes Semedo ${ }^{3}$} \\ Universidade de Cabo Verde, Docente da Universidade de Cabo Verde; Presidente do \\ Conselho Diretivo do Departamento de Ciências e Tecnologia

\section{Catia Piccolo Devechi ${ }^{4}$} \\ Universidade de Brasília (UnB), Docente do Programa de Pós-graduação em Educação
}

\begin{abstract}
Resumo: No presente estudo, organizado na perspectiva dos estudos comparados, pretendemos discutir acerca dos princípios e critérios orientadores dos processos de avaliação externa que incidem sobre a organização das instituições de Educação Superior do Brasil e de Cabo Verde. Analisamos como cada País tem regulamentado a relação entre a Educação Superior e a sociedade e atendido seu compromisso com as políticas públicas. Concluímos que a criação de sistemas de avaliação externa no Brasil e em Cabo Verde vincula-se à necessidade de regulação dos Estados e à indução da qualidade dos sistemas educacionais, em um cenário de diversificação de modelos

\footnotetext{
${ }^{1}$ Agradecemos o apoio e o financiamento do Programa Pró-mobilidade Internacional CAPES/AULP e ao CNPq.

${ }^{2}$ Doutora em Educação pela Pontifícia Universidade Católica do Rio Grande do Sul (PUCRS); Mestre em Educação pela Universidade Federal de Santa Maria (UFSM).

${ }^{3}$ Doutor e Mestre em Didática da Matemática pela Universidade de Lisboa, Portugal.

${ }^{4}$ Doutora em Educação pela Universidade Federal de Santa Catarina (UFSC); Mestre em Educação pela Universidade Federal de Santa Maria (UFSM).
} 
institucionais, de expansão do acesso à Educação Superior e de integração e de reconhecimento internacional.

Palavras-chave: Avaliação externa. Educação Superior. Estado. Qualidade.

Abstract: In this current study, worked out from the perspective of comparative studies, we aimed to discuss about the principles and guiding criteria of external evaluation processes that focus on the organization of Higher Education Institutions in Brazil and Cape Verde. We analyzed how each country has regulated the relationship between Higher Education and society and how each of them have committed itself with the public policies. We concluded that the creation of external evaluation systems in Brazil and Cape Verde is linked to the need to set up regulation by both States and to the induction of the quality of the educational systems, in a scenario of diversification of institutional models, taking into account the expansion of the access to Higher Education, the integration and international recognition.

Keywords: External evaluation. Higher Education. State. Quality.

Resumen: En el presente estudio, organizado en la perspectiva de los estudios comparados, pretendemos discutir los principios y criterios orientadores de los procesos de evaluación externa que inciden sobre la organización de las instituciones de Educación Superior de Brasil y de Cabo Verde. Analizamos cómo cada país tiene reglamentada la relación entre la Educación Superior y la sociedad, y cómo ha atendido su compromiso con las políticas públicas. Concluimos que la creación de sistemas de evaluación externa, en Brasil y en Cabo Verde, se vincula a la necesidad de regulación de los Estados y a la inducción de la calidad de los sistemas educacionales, en un escenario de diversificación de modelos institucionales, de expansión del acceso a la Educación Superior y de integración y de reconocimiento internacional.

Palabras clave: Evaluación externa. Educación Superior. Estado. Calidad.

\section{CONSIDERAÇÕES INICIAIS}

O campo da avaliação é conflituoso e contraditório, pois coexistem diferentes interesses e modos de regulação que colocam em tensão o lugar do Estado, do mercado e da comunidade (TEODORO, 2013). Por isso, Dias Sobrinho (2012, p. 1) expressa que “[...] a avaliação é hoje uma política pública utilizada como estratégia de poder" e vem consagrando, no contexto neoliberal de internacionalização (SCHRIEWER, 1995; MOROSINI, 2006) e de globalização da economia, as alian- 
ças entre os Estados, os organismos multilaterais e os interesses econômicos (BALL, 2001; DALE, 2004). Sua função operacional, configurada no âmbito das reformas da administração pública e das políticas educacionais (TEODORO, 2011), expressa-se como uma estratégia para assegurar referenciais de qualidade, sustentados pela introdução, consolidação e ampliação de mecanismos de avaliação em larga escala.

Essa indução às políticas de avaliação pode ser observada principalmente a partir de 1970, com os estudos realizados pela Organização das Nações Unidas para a Educação, a Ciência e a Cultura (Unesco), Organização para a Cooperação e Desenvolvimento Econômico (OCDE) e Banco Mundial (SCHRIEWER, 1995), os quais "[...] mostravam uma relação direta entre o nível de desenvolvimento do país e o nível de escolaridade da população" (RODRIGUES; MACHADO; ARAÚJO, 2011, p. 2), expressando a necessidade de democratizar o acesso à Educação Superior, tendo como decorrência sua expansão (TEODORO, 2013). Assim, as tendências à internacionalização e à globalização se manifestam em áreas cruciais para as sociedades modernas, como a educação, mobilizando ações de indução, controle e reflexão voltadas à organização dos sistemas educacionais na forma de políticas, pesquisas e teorias. "Surgem, assim, tratados, documentos normativos, declarações, estudos, exames, orientações e programas de cooperação, cuja finalidade é prescrever os modos de operar as reformas e de elaborar as políticas educativas dos diferentes países." (CARVALHO, 2014, p. 135).

Nesse cenário, no final da década de 1980, em virtude das crises na economia mundial, muitos Estados reduziram os investimentos públicos nas Instituições de Ensino Superior (IESs) e investiram esforços no aumento da eficiência dos recursos. Os efeitos dessas mudanças na administração pública impulsionaram o aumento quantitativo e diversificado da oferta e a interiorização da Educação Superior, principalmente privada, expressando a vinculação da ideologia neoliberal às políticas de avaliação e de accountability. Schneider e Rostirola (2015, p. 495) explicam que, nos estágios subsequentes, a avaliação foi marcada “[...] pela aderência dos países a formas de avaliação internacional, e, o terceiro, o estágio atual, pelos processos de transnacionalização da prática avaliativa."

Destacam-se, nos anos 1990, as ações da Organização para a Cooperação e Desenvolvimento Econômico (OCDE) no campo das avaliações internacionais em larga escala - Programme for International Student Assessment (PISA). Dias Sobrinho (2012, p. 7) considera que “[...] modelos externos e abstratamente universais podem ter sua validade, desde que não sejam tomados como inquestionáveis [...]" A criação de sistemas de avaliação externa, de forma geral, vincula-se à necessidade de 
regulação dos Estados e à indução da qualidade dos sistemas educacionais, em um cenário de diversificação de modelos institucionais, de expansão das instituições e do acesso à Educação Superior, de integração e de reconhecimento internacional. Nesse contexto, a expansão ocorreu por meio da diversificação de modelos institucionais e da ampliação do modelo privado, provocando, também, um desequilíbrio do binômio qualidade-quantidade (VERHINE; FREITAS, 2012).

A avaliação vem sendo utilizada para orientar as políticas publicas no setor e garantir a excelência das instituições diante das necessidades do desenvolvimento do sistema da economia. Trata-se de um fato que tem minimizado a autonomia das universidades, que, empenhadas no atendimento de critérios objetivos, têm se transformado, muitas vezes, em espaços de gerenciamento numérico e homogeneização em detrimento da formação humana e científica.

Nesse sentido, emerge a articulação deste estudo com a Educação Comparada (COWEN; KAZAMIAS; ULTERHALTER, 2012a; MALET, 2004). Cowen (2012) explica que um dos esforços desta tem sido redefinir conceitos interpretativos para a compreensão das novas relações entre o nacional, o internacional e o global e que "ler o global" "[...] significa a seleção de uma agenda de trabalho acadêmico, a identificação de ansiedades e perplexidades inseridas em uma interpretação das partes estrangeiras do mundo que são vistas - no sentido de que tais localidades tornam-se deliberadamente visíveis." (COWEN, 2012a, p. 391). Assim, considera que

[...] o problema clássico da educação comparada é constituído de três momentos: (i) transferência; (ii) tradução - o problema duplamente osmótico da inclusão de ideias, princípios, políticas e práticas educacionais em um lugar e de inseri-los em outro contexto social [...] (iii) a transformação do fenômeno educacional, à medida que cresce socialmente, osmoticamente nesse novo contexto social. (COWEN, 2012a, p. 409-410).

Reveste-se, ainda, de maior significado se considerarmos que "[...] o Estado continua a ser o principal agente de seleção e tradução dos imperativos globais [...] Assim, a seleção e a tradução de imperativos educacionais globais são, principalmente, processos locais que estão sujeitos às restrições de atores e de condições locais." (LAW, 2012, p. 315).

A avaliação externa tem sido o principal instrumento para a "[...] organização e implementação das reformas educacionais em um cenário em que coexistem movimentos de retração dos Estados, remetendo às agências de acreditação e de avaliação a regulação das políticas públicas" (TEODORO, 2013); e tendências de am- 
pliação das políticas indutoras e de controle dos Estados, orquestrando um conjunto de estratégias que caracterizam o Estado Avaliador (NEAVE, 2012), que concentra sob sua administração as estratégias de desenvolvimento, definindo e orientando a execução da política nacional de Educação Superior, considerando a qualidade das instituições como de interesse público. Como controlador, o "[...] Estado teria a legitimidade para, de forma centralizada, estabelecer as políticas públicas de educação, os planos e a legislação complementar, no âmbito do princípio da homogeneidade legal, assumindo o controlo das IES.” (MENDES; SILVA, 2011, p. 6). Como supervisor, segundo os mesmos autores, o Estado "[...] obedece ao princípio da diversidade e da aceitação do mercado como elemento para a diversificação das instituições de ensino superior, onde o Estado exerce uma supervisão mais distanciada, estabelecendo os parâmetros da qualidade", creditando maior autonomia às IESs, e os resultados da avaliação são usados para a tomada de decisões.

Nesse cenário, a Comunidade dos Países de Língua Portuguesa (CPLP) e a das instituições que fazem parte da Associação das Universidades de Língua Portuguesa (AULP) (FERRÃO, 2013) vêm discutindo a cooperação e o desenvolvimento dos países lusófonos, especialmente na área da educação (TAUCHEN; MENDES; DEVECHI, 2015), reconhecendo a necessidade de percepções mais locais/globais e interculturais dos sistemas de educação e de ensino. Nesse sentido, “[...] os governos, ao participar das conferências internacionais, acolhem as recomendações, firmam compromissos e assumem obrigações de assegurar metas e objetivos propostos.' (CARVALHO, 2014, p. 135). Em concomitância, por meio dos acordos de cooperação e de desenvolvimento, recebem apoio técnico e financeiro dos países parceiros e das organizações multilaterais, para promoverem reformas nos sistemas de ensino alinhadas às exigências internacionais. Nesse contexto, o Brasil vem organizando os eixos estruturantes para a construção do Programa Educação como Ponte Estratégica Brasil-África, baseado nas ações que vêm sendo desenvolvidas no âmbito da cooperação com os Países Africanos de Língua Oficial Portuguesa (BRASIL, 2013). Um dos objetivos do Programa é “"[...] ampliar a comunicação entre áreas técnicas ligadas às políticas educacionais, de maneira que as ações sejam desenvolvidas de maneira coordenada entre os países." (BRASIL, 2013). Diversas ações estão em fase de implantação, e, em Cabo Verde, destacamos o desenvolvimento do projeto Qualidade da Educação Superior - Criação do Sistema de avaliação em Cabo Verde, envolvendo o Instituto Nacional de Estudos e Pesquisas Educacionais Anísio Teixeira (Inep) e o Ministério da Educação Ciência e Inovação de Cabo Verde. Assim, no presente estudo, decorrente das ações de cooperação internacional e de investigação científica 
desenvolvidas a partir do Programa Pró-Mobilidade Internacional CAPES/AULP entre a Universidade Federal do Rio Grande (FURG), Brasil, e a Universidade de Cabo Verde (UniCV), intenciona-se discutir acerca dos princípios e critérios orientadores dos processos de avaliação externa que incidem sobre a organização das instituições de Educação Superior dos dois Países, inspirados nos estudos em educação comparada (COWEN; KAZAMIAS; ULTERHALTER, 2012; MALET, 2004). Nesse sentido, buscamos, por meio de um estudo comparado, apontar possibilidades para renovar os saberes sobre modelos de avaliação, problematizando suas intencionalidades e adequação à atual realidade da Educação Superior em ambos os países.

\section{SISTEMA DE AVALIAÇÃO EXTERNA NO BRASIL}

A avaliação externa na Educação Superior brasileira teve início em 1976 com a avaliação da pós-graduação, realizada pela Coordenação de Aperfeiçoamento de Pessoal de Nível Superior (Capes), em virtude da distribuição das bolsas que, da concessão individual, passou a ser institucional (FERREIRA; MOREIRA, 2002). Atualmente, o processo de avaliação é coordenado pela Diretoria de Avaliação da Capes e realizado por Comissões de Área, constituídas por membros da própria comunidade científica, e os resultados dessa avaliação norteiam a concessão de fomento aos programas de pós-graduação que estão diretamente relacionados aos conceitos obtidos pelos cursos, independente do status jurídico da instituição.

A avaliação das instituições de Educação Superior e dos cursos de graduação, no entanto, foi organizada a partir da década de 1990 e ampliada com a aprovação da Lei n. 10.861, de 14 de abril de 2004, que instituiu o Sistema Nacional de Avaliação da Educação Superior (Sinaes), atribuindo à Comissão Nacional de Avaliação da Educação Superior (Conaes) a coordenação e a supervisão do Sinaes, com a competência de definir diretrizes, critérios e estratégias para tal empreendimento. "A proposição desse sistema teve por objetivo construir um sistema nacional de avaliação que articulasse a regulação e a avaliação educativa, esta última numa perspectiva mais formativa e voltada para a atribuição de juízos de valor e mérito [...]" (PEIXOTO, 2011, p. 14), contemplando a participação dos agentes educativos e as dimensões interna e externa no processo de avaliação. Dias Sobrinho (2010) explica que, na visão do Sinaes, a articulação entre regulação e avaliação seria contemplada por um conjunto integrado de instrumentos de avaliação - avaliação institucional (autoavaliação e avaliação externa), avaliação dos cursos de graduação e avaliação de desempenho dos estudantes (Enade) -, produzindo informações para as ações regulatórias do Conselho 
Nacional de Educação e do Ministério da Educação, que expressam as prerrogativas do Estado no que se refere ao credenciamento e recredenciamento das instituições, autorização e reconhecimento dos cursos e avaliação formativa, que, destacada por Peixoto (2011), conta com a participação da comunidade acadêmica. Conforme afirma Dias Sobrinho (2010, p. 208), “[...] com base nos resultados globais da avaliação, e não em um único instrumento, a regulação seria mais confiável, fundamentada e eficaz do ponto de vista da relevância social e da pertinência essenciais à construção da qualidade do sistema de educação superior.” Logo, o processo de avaliação vincula-se às intenções de incremento da qualidade do sistema educacional brasileiro.

Cabe-nos salientar, contudo, que a polissemia de entendimentos sobre a qualidade da educação não confere universalidade ao conceito. Bertolin (2009) sugere a predominância de três tendências: a economicista, vinculada ao crescimento da economia, empregabilidade e eficiência, a pluralista, voltada ao desenvolvimento econômico, cultural, social e democrático, considerando diferenciação, pertinência e participação, e a equidade, orientada para a promoção da igualdade de oportunidades e coesão social.

Morosini e Franco (2012) também analisaram as abordagens de qualidade presente nas políticas e nas estratégias nacionais vinculadas à Educação Superior e identificaram: a abordagem técnica de qualidade, voltada à identificação de resultados e consequente classificação e comparabilidade entre cursos e instituições, e a abordagem de qualidade social, vinculada à expansão do acesso, inclusão e inserção social. Para as autoras, essas duas abordagens estão presentes na proposição do Sinaes. Na avaliação de desempenho dos estudantes, por exemplo, é possível perceber a incidência da abordagem técnica, quando intenciona verificar os resultados de desempenho dos estudantes ao longo do curso. Essa avaliação de desempenho, mais recentemente, vem expressando uma forte tendência para o ranking dos cursos e das instituições, principalmente a partir da Portaria Normativa n. 12/2008 do Ministério da Educação, que instituiu o

Índice Geral de Cursos da Instituição de Educação Superior (IGC), que consolida informações relativas aos cursos superiores constantes dos cadastros, censo e avaliações oficiais disponíveis no Instituto Nacional de Estudos e Pesquisas Anísio Teixeira (INEP) e na Coordenação de Aperfeiçoamento de Pessoal de Nível Superior (CAPES). (BRASIL, 2008, p. 1).

Ou seja, ao realizar-se uma fusão de indicadores da graduação e da pós-graduação, os resultados têm fortalecido ações de comparação e de classificação en- 
tre as instituições. Dias Sobrinho (2010) explica que a própria Lei dos Sinaes “[...] acabou oferecendo um argumento para a elaboração de rankings, ao prever a escala de cinco níveis para os cursos e para o desempenho dos estudantes no ENADE". No entanto, além da qualidade técnica, Morosini e Franco (2012) destacam que o IGC pode ser um indicador para a identificação de aspectos deficitários, potencializando ações estratégicas e a mudança qualitativa das instituições e do sistema educacional, aproximando-se da abordagem da qualidade social. Essa abordagem pode ser evidenciada pelas políticas indutoras, promovidas pelo Governo brasileiro nos últimos anos, como a política de cotas, o Programa Universidade para Todos (Prouni) e o Programa de Apoio a Planos de Reestruturação e Expansão das Universidades Federais (Reuni), entre outros, que contemplam estratégias de expansão e de acesso à Educação Superior.

Cabe-nos salientar que a abordagem da qualidade social foi balizadora da concepção do Sinaes e pode ser evidenciada nos princípios que regem a avaliação (BRASIL, 2006, p. 11): “[...] reponsabilidade social com a qualidade da educação superior, reconhecimento à diversidade do sistema, respeito à identidade, à missão e à história das intituições, globalidade insitucional, continuidade do processo avaliativo como instrumento de política educacional" para as instituições e para o sistema. Expressa uma concepção de avaliação voltada para a "[...] construção e consolidação da qualidade, da participação e da ética na educação superior [...]” (BRASIL, 2006, p. 12). Para Dias Sobrinho (2010, p. 210), “[...] na concepção original do SINAES, a educação transcende o desempenho estudantil em provas estáticas, [...] buscando significados amplos da formação humana integral e pondo em questão a responsabilidade social das IES." No entanto, muitas dificuldades foram encontradas na implantação desse sistema: a inexistência de uma cultura institucional de avaliação processual e formativa; as dificuldades em criar uma cultura de participação nas insitutições; a não adesão, em um primeiro momento, de instituições municipais e estaduais de educação superior e a falta de balizadores para o desenvolvimento das IESs, como o Plano de Desenvolvimento Institucional (PDI); a composição do banco de avaliadores externos, que nem sempre são selecionados conforme critérios sugeridos nos regulamentos, entre outros aspectos. Dias Sobrinho (2010, p. 215) considera que, apesar das dificuldades, o período inicial de implantação "[...] não se limitava à conformação a normas burocrático-legais. Entretanto, as recentes iniciativas do INEP, com o aval do CONAES, tendem a interromper esse processo participativo e retomar o paradigma técnico-burocrático." 
A avaliação externa das IESs, conforme o Sinaes, constitui-se por meio de bases de informação quantitativa, informada pelas IES, referente à infraestrutura física, recursos humanos, cadastro e censo da Educação Superior e avaliações já realizadas pelo MEC, e qualitativa, decorrente da análise das informações quantitativas e das comparações entre o que a IES propõe e suas capacidades, a partir das interações entre os avaliadores e os agentes educativos. As informações qualitativas vinculam-se diretamente ao cotejamento entre as concepções expressas no Projeto Pedagógico Institucional (PPI), as metas do Plano de Desenvolvimento Institucional (PDI) e o nível de realização alcançado pela IES com o objetivo de captar as dinâmicas institucionais na direção da qualidade das 10 dimensões estabelecidas pelo Sistema Nacional de Avaliação: missão e Plano de Desenvolvimento Institucional; políticas, normas e estímulos para o ensino, a pesquisa e a extensão; responsabilidade social; comunicação com a sociedade; política de pessoal, carreira, aperfeiçoamento e condições de trabalho; organização e gestão da instituição; infraestrutura física e estruturas de apoio; planejamento e avaliação; políticas de atendimento aos estudantes e sustentabilidade financeira. Cada indicador é pontuado por uma referência preestabelecida, podendo o avaliador externo realizar uma apreciação qualitativa das dimensões observadas.

Os avaliadores para a constituição da Comissão de Avaliação in loco são cadastrados no Banco de Avaliadores (BASis) (Portaria MEC n. 1.027/2006) do Sinaes, que se constitui em cadastro nacional e único de avaliadores, institucionais e de curso, selecionados pelo Instituto Nacional de Estudos e Pesquisas Anísio Teixeira (Inep). O BASis será composto pela seleção de: "I - avaliadores indicados pelos conselhos superiores das instituições de educação superior; II - avaliadores indicados pelos colegiados responsáveis pelos cursos de graduação; III - avaliadores indicados por entidades científicas ou educacionais cadastradas no INEP; IV - avaliadores inscritos." (BRASIL, 2006). Conforme Art. 5 da referida Portaria, o perfil acadêmico e profissional dos avaliadores deverá contemplar: titulação mínima de doutor, mas poderão ser selecionados avaliadores sem essa titulação, em razão das características próprias dos cursos avaliados, produção acadêmica e intelectual, reputação ilibada, experiência em gestão educacional de, no mínimo, três anos, entre outros aspectos. Os avaliadores são definidos por sorteio e, conforme o Art. 6, § 4, “[...] não poderão ser oriundos da mesma unidade da federação da instituição de educação superior ou do curso de graduação em avaliação, e pelo menos um avaliador deverá ser oriundo da mesma região." Os avaliadores selecionados também passam por um processo de capacitação para utilização dos instrumentos de avaliação e elaboração dos relatórios de avaliação. Dias Sobrinho (2010, p. 215) considera que 
[...] muitos aspectos do SINAES foram considerados pelo INEP de difícil operacionalização e demasiadamente subjetivos para caber em escalas objetivas. Outras dificuldades ocorreram em razão da falta de estrutura adequada do INEP ou carência de pessoal acadêmico com boa formação em avaliação, tanto na administração central quanto nas IES.

O autor também alerta para a frágil tradição avaliativa do País e os desafios da diversidade em um país de dimensões continentais. Outro aspecto que merece destaque é o distanciamento temporal entre a realização das avaliações e a divulgação dos resultados, ou seja, as avaliações realizadas em 2013, por exemplo, foram divulgadas apenas em dezembro de 2014. Ou seja, as providências institucionais serão discutidas e, na melhor das hipóteses, começarão a ser implementadas em 2015. Neste período, entre 2013 e 2015, milhares de profissionais serão titulados em instituições que, muitas vezes, não possuem a qualidade mínima para cumprir suas finalidades.

\section{SISTEMA DE AVALIAÇÃO EXTERNA EM CABO VERDE}

O Ensino Superior em Cabo Verde teve início após a independência, vinculado aos planos de desenvolvimento do País (CARDOSO, 2014). O primeiro estabelecimento desse nível foi decorrente da organização do Curso de Formação de Professores do Ensino Secundário, em 1979 (Decreto n. 70/79). Conforme destaca Varela (2013, p. 5), “[...] o modelo cabo-verdiano segue, de perto, o português, com poucas nuances."

Atualmente, o Ensino Superior compreende o ensino universitário e o ensino politécnico (Art. 31 da Lei n. 103) e tem como objetivos

[...] desenvolver capacidade de concepção, de inovação, de investigação, de análise crítica e de decisão; formar diplomados nas diferentes áreas de conhecimento; estimular a criação cultural e o desenvolvimento do espírito científico e do pensamento reflexivo; promover a divulgação de conhecimentos culturais, científicos e técnicos que constituem património da humanidade; [entre outros]. (CABO VERDE, 1990).

Nesse cenário,

[...] nove instituições do ensino superior (uma pública e oito privadas) foram criadas nos últimos dez anos, aumentando assim a Taxa Bruta de Escolarização (TBE) do ensino superior para cerca de 20 por cento. Cabo Verde está também em vias de alcançar os Objectivos do Milénio para o Desenvolvimento até 
2015. Estas são conquistas notáveis para uma pequena nação de meio milhão de habitantes que tem recursos naturais muito limitados, um clima árido, uma emigração substancial, e uma população dispersa em dez ilhas diferentes. (BANCO MUNDIAL, 2012, p. 12).

Cabe-nos salientar que o "[...] Ensino Superior privado acolhe a maioria dos estudantes universitários, constituindo por isso um bem nacional importante, e que o governo pode tomar medidas adequadas de interesse nacional para o seu desenvolvimento." (BANCO MUNDIAL, 2012, p. 9). É nesse contexto de ampliação da oferta e do número de IES que surge, em 2011, o projeto Garantia da Qualidade: criação do sistema de avaliação do ensino superior em Cabo Verde, no âmbito da cooperação Brasil-África. O projeto envolve a parceria entre o Instituto Nacional de Estudos e Pesquisas Educacionais Anísio Teixeira (Inep), o Ministério do Ensino Superior, Ciência e Inovação (MESCI) de Cabo Verde, por meio da Direção-Geral do Ensino Superior (DGES), e o apoio da Agência Brasileira de Cooperação (ABC) (BRITO, 2013).

Brito (2013) informa que foram realizados seminários, com a participação dos docentes, gestores das instituições de ensino superior de Cabo Verde e técnicos do MESCI e da equipe de apoio e orientação do Inep, para a construção dos indicadores e dos instrumentos de avaliação. O primeiro seminário ocorreu em fevereiro de 2013, no qual se consensualizou sobre a importância da avaliação como instrumento indutor da qualidade e a produção de proposta de indicadores para a avaliação. No mês de abril, ocorreu o segundo Seminário de Capacitação dos membros do Conselho para a Qualidade Acadêmica (Decreto-Lei n. 20/2012). O encontro procurou integrar as percepções dos participantes sobre a construção das diretrizes e princípios do sistema de avaliação para Cabo Verde. Também foram discutidos os conceitos e fundamentos da qualidade do ensino e a experiência brasileira na implantação da Comissão Nacional de Avaliação da Educação Superior (Conaes). O terceiro seminário ocorreu no mês de outubro, sendo dedicado ao processo de elaboração dos instrumentos de avaliação institucional externa, culminando com a produção do Guião para a Avaliação Institucional Externa e Diretrizes do Sistema Nacional de Garantia de Qualidade do Ensino Superior.

Foram definidas cinco dimensões institucionais a avaliar: o Plano Estratégico de Desenvolvimento Institucional e autoavaliação, gestão institucional, infraestrutura, política acadêmica e política de pessoal. A avaliação externa também é subsidiada pelo relatório de autoavaliação das IES e dos resultados da avaliação in loco 
das comissões de avaliação, que possuem como base os critérios descritos no Guião de Avaliação (CABO VERDE, 2014b).

A seleção pública dos profissionais para integrar o Banco de Avaliadores de Instituições de Ensino Superior de Cabo Verde foi regulamentada pelo MESCI, por meio de edital (Despacho n. 6/2014), prevendo os seguintes requisitos: ter doutorado (preferencialmente) ou mestrado com experiência mínima de cinco anos no ensino superior e, como requisitos alternativos, ter experiência profissional em avaliação e experiência na gestão do ensino superior. O processo de seleção ficou a cargo do Conselho para a Qualidade Acadêmica, e os selecionados participarão de formação específica, condição necessária para participar do processo de avaliação das instituições.

Conforme destaca o estudo do Banco Mundial, Construindo o Futuro: Como é que o Ensino Superior pode contribuir para a agenda de transformação económica e social de Cabo Verde,

[...] o monitoramento da qualidade do ensino superior é um desafio particular em Estados pequenos como Cabo Verde. Isto porque esses Estados frequentemente carecem de profissionais devidamente qualificados para a tarefa e, no âmbito dos métodos normalmente usados de revisão pelos pares, eles enfrentam o desafio de evitar conflitos de interesse no seio de uma pequena comunidade académica. Por estas razões, deve-se ter o cuidado de evitar a importação pura e simples dos sistemas de garantia de qualidade dos países de maior dimensão. (BANCO MUNDIAL, 2012, p. 16).

O documento também adverte que é necessário considerar as capacidades locais na concepção e na implementação do sistema de garantia da qualidade.

Nas Diretivas do Sistema Nacional de Garantia da Qualidade do Ensino Superior (Snaqes), evidencia-se que a aposta na qualidade de desempenho das instituições se vincula às políticas e aos normativos definidos pelo Estado, com ênfase nos processos de regulação do sistema, de acreditação e avaliação das instituições e dos cursos, com a interligação dos sistemas de autoavaliação e de heteroavaliação. A concepção do Sistema estruturou-se em torno da visão estratégica da qualidade, entendida e aferida em uma perspectiva multifatorial e multidimensional, tendo como referenciais a legislação educacional, as diretivas institucionais do Estado, os estatutos e planos estratégicos das instituições, cuja observância é espelhada nos instrumentos de avaliação e de monitoramento das instituições e dos cursos. Assim, “[...] o SNAQES compreende a avaliação institucional interna e externa das instituições e cursos, 
devendo garantir o caráter público e transparente de todos os procedimentos, dados e resultados dos processos avaliativos [...]" (CABO VERDE, 2014b, p. 5).

Assim, analisando as dimensões e os indicadores que constituem os sistemas de avaliação do Sinaes e do Snaqes, observamos grande correspondência e similaridade, conforme destacamos na sequência:

Esquema 1 - Dimensões e indicadores dos sistemas de avaliação do Sinaes e do Snaqes

\section{SINAES}

- Missão e Plano de Desenvolvimento Institucional

- Políticas, normas e estímulos para o ensino, a pesquisa e a extensão

- Responsabilidade social

- Comunicação com a sociedade

- Política de pessoal, carreira, aperfeiçoamento e condições de trabalho

- Organização e gestão da instituição

- Infraestrutura física e estruturas de apoío

- Planejamento e avaliação

- Políticas de atendimento aos estudantes

- Sustentabilidade financeira

Fonte: os autores.

As dimensões que integram o Snaqes são em menor número, mas os indicadores que as integram expressam correspondência com as dimensões dos Sinaes. Cabe-nos destacar, contudo, que a análise pormenorizada dos indicadores do Snaqes revela uma grande preocupação e alinhamento com as características históricas e culturais de Cabo Verde no que diz respeito à internacionalização e recepção de estudantes estrangeiros.

\section{A AVAliaÇão NAS RELAÇÕES ENTRE O ESTAdo E AS IES}

Conforme destacam Mendes e Silva (2011, p. 5), “[...] a avaliação é associada ao controlo e garantia da qualidade educativa, salvaguardando o legítimo interesse público." Ou seja, emerge a tendência de um Estado Avaliador, que concentra, 
sob sua administração, as estratégias de desenvolvimento, definindo e orientando a execução da política nacional de ES, considerando a qualidade das IESs como de interesse público. Paralelamente, o Estado acentua a necessidade de as IESs promoverem a avaliação interna. Os autores destacam que as relações entre o Estado e as IESs, no âmbito da avaliação, podem assumir contornos de controle ou supervisão. Como controlador, o "Estado teria a legitimidade para, de forma centralizada, estabelecer as políticas públicas de educação, os planos e a legislação complementar, no âmbito do princípio da homogeneidade legal, assumindo o controlo das IES.” (MENDES e SILVA, 2011, p. 6) Como supervisor, o Estado “[...] obedece ao princípio da diversidade e da aceitação do mercado como elemento para a diversificação das instituições de ensino superior, onde o Estado exerce uma supervisão mais distanciada, estabelecendo os parâmetros da qualidade." (idem) Como supervisor, credita-se maior autonomia às IESs, e os resultados da avaliação são usados para a tomada de decisões. Graça (2012, p. 4) entende que a "Avaliação (Acção e o efeito de assinalar, estimar, apreciar ou calcular o valor de algo) e Monitoria (prática de avaliação e acompanhamento de desempenho) da Qualidade de Ensino constituem recursos que justifica-se plenamente [...]" na produção de dados para a supervisão. Popkewitz (1992, p. 95-97) explica que "[...] a avaliação é uma estratégia estatal que aparece como parte da produção de ideias em um campo social. Esta produção inclui as relações de poder. [...] A avaliação forma parte da regulação. Controle e governo do Estado [...] cumpre fins de política [...]"

A análise realizada por Mendes e Silva (2011, p. 12) destaca que para além das relações de poder entre o Estado e a autonomia das IESs, a gestão universitária poderá estabelecer “[...] agendas próprias segundo os seus Planos de Desenvolvimento Institucional.” Ou seja, a avaliação institucional como estratégia para acompanhamento e regulação dos objetivos e metas definidos no PDI, produzindo informação sobre a qualidade da instituição.

Rodrigues, Machado e Araújo (2011, p. 8) consideram que a "[...] avaliação externa, para além de fornecer um feedback às IES, destina-se às atividades de regulação e de controle do ensino superior brasileiro, conforme determinação legal." Ou seja, por meio da avaliação, o Estado regula a entrada das IESs no sistema de Educação Superior, por meio da avaliação do credenciamento e da renovação de funcionamento das IESs, e autoriza o reconhecimento e renovação deste nos cursos de graduação (COELHO, 2012; RODRIGUES; MACHADO; ARAÚJO, 2011). Assim, a avaliação voltada à melhoria permanente da qualidade é utilizada, também, como suporte à regulação e à supervisão, isto é, seus resultados determinam ações regulatórias e atos de supervisão. 
Nesse sentido, o estudo de Coelho (2012), referindo-se à atuação das comissões externas de avaliação, no âmbito do Sinaes, alerta-nos para os riscos decorrentes das interações entre os sujeitos educativos, em que, na situação de assimetria, o poder do avaliador pode se impor sobre o avaliado. "Caso esse (des)equilíbrio seja a tônica dos momentos da avaliação in loco, ao invés de formativa a avaliação passa a ser repressora e fiscalizatória o que impede a efetiva e adequada avaliação [...]" (COELHO, 2012, p. 5). Mendonça et al. (2012, p. 11) analisam que, no sistema brasileiro, em que coexistem diferentes formas de organização administrativa e institucionais de educação superior, a avaliação por critérios e dimensões homogeneizadoras " [...] aumenta o fosso entre instituições de portes e amplitudes diferenciadas, o que, certamente, traz consequências negativas em termos de qualidade da educação que elas propiciam."

Rodrigues, Machado e Araújo (2011, p. 10) consideram que "[...] o processo de avaliação deveria ocorrer de maneira independente e paralela à função regulatória do Estado", e que, por isso, essa função é muito criticada. Sugerem que a avaliação institucional deve ser participativa e questionam se há “[...] espaço real para uma forma de exercício de cidadania, de aprendizagem da democracia." (RODRIGUES; MACHADO; ARAÚJO, 2011, p. 10). Afirmam que a avaliação e a regulação possuem objetivos e procedimentos divergentes e, por isso, deveriam ser trabalhadas de forma diferenciada. A regulação teria a função de " [...] analisar e sanar problemas estruturais, pedagógicos e de gestão universitária, de modo a punir, sempre que necessário, os atores causadores de ações que venham prejudicar o desenvolvimento acadêmico.” (RODRIGUES; MACHADO; ARAÚJO, 2011, p. 10). Dias Sobrinho (2012, p. 7) expressa que

[...] modelos externos e abstratamente universais podem ter sua validade, desde que não sejam tomados como inquestionáveis, nem adotados sem adaptação aos contextos culturais, ideológicos e políticos de cada país e sem o devido respeito à missão e às prioridades e especificidades de cada instituição.

Nessa perspectiva, Coelho (2012, p. 8-9) destaca que o princípio da diversidade da educação superior é reiterado várias vezes nas orientações do Sinaes, mas alerta que "[...] os indicadores tendem à padronização o que responde a critérios avaliativos da objetividade e comparabilidade, decorrentes de princípios do fazer científico positivista que tradicionalmente embasa processos avaliativos, principalmente os de larga escala." 
A avaliação, a partir da análise de Dias Sobrinho (2012, p. 7), não está restritamente vinculada aos processos de diagnóstico e controle, mas, sobretudo, ao " [...] processo coletivo de interrogação sobre as causalidades, as dinâmicas pedagógicas e cognitivas, sobre o significado humano e social da formação e do conhecimento, sobre os contextos de realização e as potencialidades que a universidade carrega [...]"

\section{CONSIDERAÇÕES FINAIS: UMA APRENDIZAGEM COMUNICATIVA ENTRE OS SISTEMAS DE AVALIAÇÃO EXTERNA DAS IESS}

A criação de sistemas de avaliação externa no Brasil e em Cabo Verde, assim como em outros países, vincula-se à necessidade de regulação dos Estados e à indução da qualidade dos sistemas educacionais, em um cenário de diversificação de modelos institucionais, de expansão do acesso à Educação Superior, de integração e de reconhecimento internacional, fortemente influenciado pelo Processo de Bolonha, que busca reunir, em um sistema unificado de ensino, os diferentes sistemas de Ensino Superior.

Tal dinâmica de unificação tem sido motivo de crítica, tendo em vista a desconsideração de contextos particulares. Em se tratando do Brasil e de Cabo Verde, apesar da identidade da língua, é mister considerar que se trata de contextos bem diferentes, considerando, principalmente, a história e a cultura dos países, a diferença na dimensão espacial e populacional, as características de desenvolvimento socioeconômico e a organização dos sistemas educacionais. Contudo, a expansão significativa da Educação Superior, a partir dos anos 1990, no Brasil, e a partir de 2000, em Cabo Verde, evidenciou as demandas sociais por oportunidades de ensino, às quais desencadearam o aumento nos investimentos dos Estados com a Educação Superior pública, provocando pressões por maior transparência e responsabilização no uso dos recursos públicos. Nesse contexto, a expansão da Educação Superior ocorreu por meio da diversificação de modelos institucionais e ampliação do modelo privado, provocando um desequilíbrio do binômio qualidade-quantidade (VERHINE; FREITAS, 2012).

A avaliação das IESs não decorre de uma necessidade ou iniciativa voluntária, mas das políticas de Estado, que definem, embora de forma relativamente participativa, os padrões mínimos de referência. Assim, a avaliação externa vem se firmando como um instrumento de regulação da qualidade das IESs e de gestão da agenda educacional dos dois países. 
Consideramos que o contexto econômico, os aspectos culturais e as prioridades do desenvolvimento, ancorados em uma agenda estratégica que sirva aos interesses dos respectivos Estados, não devem demover as principais variáveis de normalização conducentes à qualidade, internacionalmente aceite para as instituições do ensino superior e, particularmente, pelas universidades. Os agentes ativos das instituições, de forma explícita, quer em uma avaliação endógena, quer em uma avaliação externa, têm responsabilidades diferentes relativamente a distintas variáveis, considerando os seus conhecimentos e propósitos e o contexto de atuação de olhos postos em uma avaliação que leva em conta aspectos de políticas para ensino e pesquisa e extensão, responsabilidade social, missão institucional e respectivos planos de desenvolvimento institucional, gestão e figurino institucionais, políticas de integração dos estudantes e seu acompanhamento desde a entrada até a formação profissional, integração com a sociedade, mobilidade na carreira e desenvolvimento profissional e a sustentabilidade financeira, aspecto preocupante e intrínseco a todos os processos de desenvolvimento institucional das instituições do ensino superior contemporâneas.

\section{REFERÊNCIAS}

BALL, S. J. Diretrizes políticas globais e relações políticas locais em educação. Currículo sem Fronteiras, v. 1, n. 2, p. 99-116, jul./dez. 2001.

BANCO MUNDIAL. Construindo o futuro: como é que o ensino superior pode contribuir para a agenda de transformação econômica e social de Cabo Verde. Documento do Banco Mundial, 2012. Disponível em: <http://www.dgesc.gov.cv/index. php/es/estudos-sobre-es-de-cv/finish/11/19>. Acesso em: 03 abr. 2015.

BERTOLIN, J. Qualidade em educação superior: da diversidade de concepções à inexorável subjetividade conceitual. Avaliação, Campinas, Sorocaba, v. 14 n. 1, p. 127-149, mar. 2009.

BRASIL. Lei n. 10.861, de 14 de abril de 2004. Institui o Sistema Nacional de Avaliação da Educação Superior - SINAES e dá outras providências. Diário Oficial da União, Brasília, DF, 14 abr. 2004.

BRASIL. Ministério da Educação. Portaria n. 1.027, de 15 de maio de 2006. Dispõe sobre banco de avaliadores do Sistema Nacional de Avaliação da Educação Superior SINAES, a Comissão Técnica de Acompanhamento da Avaliação - CTAA e dá outras providências. Diário Oficial da União, Brasília, DF, 15 maio 2006. 
BRASIL. MEC. Gabinete do Ministro. Educação como Ponte Estratégica Brasil África. Angola, Brasil, Cabo Verde, Moçambique e São Tomé e Príncipe. Brasília, DF, 2013.

BRASIL. Portaria Normativa n. 12, de 05 de setembro de 2008. Institui o Índice Geral de Cursos da Instituição de Educação Superior (IGC). Diário Oficial da União, Brasília, DF, 05 set. 2008. Disponível em: <http://download.inep.gov.br/download/ superior/condicoesdeensino/PORTARIA_NORMATIVA_12.pdf $>$ Acesso em: 12 jan. 2015.

BRITO, A. J. Desafio da criação do sistema de avaliação do ensino superior em Cabo Verde. Fórum da Gestão do Ensino Superior nos Países e Regiões de Língua Portuguesa. Pernambuco, 2013.

CABO VERDE. Decreto-Lei n. 20/2012, de 19 de julho. Regime Jurídico das Instituições do Ensino Superior em Cabo Verde. Acesso em 5 de fevereiro de 2015. Disponível em: <https://portoncv.gov.cv/portal/page?_pageid=118,188596\& $\mathrm{dad}=$ portal\&_schema $=$ PORTAL\&p_dominio $=25 \& \mathrm{p} \_$menu $=29 \& \mathrm{p} \_$item $=279 \& \mathrm{p}$ ent_det $=1570>$. Acesso em: 05 fev. 2015.

CABO VERDE. Decreto n. 70/79, de 28 de julho de 1979. Cria o Curso de Formação de Professores do Ensino Secundário. Cabo Verde, 1979.

CABO VERDE. Lei n. 103/III, de 29 de dezembro de 1990. Aprova as Bases do Sistema Educativo de Cabo Verde (LBSE). Cabo Verde, 1990. Disponível em: $<$ https://portoncv.gov.cv/dhub/porton.por_global.open_file?p_doc_id=486>. Acesso em: 05 fev. 2015.

CABO VERDE. Ministério do Ensino Superior, Ciência e Inovação (MESCI). Direção-Geral de Ensino Superior. Despacho n. 06/2014. Seleção de avaliadores das instituições de ensino superior cabo-verdianas. Cabo Verde, 2014a. Disponível em: $<$ http://www.dgesc.gov.cv/index.php/ensino-superior-de-cv/legislacao $>$. Acesso em: 05 fev. 2015.

CABO VERDE. Ministério do Ensino Superior, Ciência e Inovação (MESCI). Direção-Geral de Ensino Superior. Despacho n. 27/2014. Regulamento de Avaliação do Ensino Superior Cabo-Verdiano. Cabo Verde, 2014b. Disponível em: $<$ http://www. dgesc.gov.cv/index.php/ensino-superior-de-cv/legislacao/finish/10/935>. Acesso em: 05 fev. 2015.

CABO VERDE. Ministério do Ensino Superior, Ciência e Inovação (MESCI). Direção-Geral de Ensino Superior. Directivas do Sistema Nacional de Garantia de Qualidade do Ensino Superior (SNAQES). Cabo Verde, 2014c. Disponível em: <http://www.dgesc.gov.cv/index.php/ensino-superior-de-cv/legislacao/finish/10/934>. Acesso em: 05 fev. 2015. 
CABO VERDE. Ministério do Ensino Superior, Ciência e Inovação (MESCI). Direção-Geral de Ensino Superior. Documento Orientador para Comissão de Avaliação Institucional Externa das IES de Cabo Verde. Disponível em: <http:// www.dgesc.gov.cv/index.php/ensino-superior-de-cv/legislacao/finish/10/933>. Acesso em: 05 fev. 2015.

CABO VERDE. Ministério do Ensino Superior, Ciência e Inovação (MESCI). Direção-Geral de Ensino Superior. Portaria. Aprova os instrumentos de avaliação institucional externa das Instituições de Ensino Superior. 2014. Disponível em: <http:// www.dgesc.gov.cv/index.php/ensino-superior-de-cv/legislacao/finish/10/936>. Acesso em: 05 fev. 2015.

CARDOSO, A. P. B. Criação do Sistema Nacional de Avaliação Institucional do Ensino Superior em Cabo Verde. In: ANPED SUL, 10., 2014, Florianópolis. Anais... Florianópolis, 2014.

CARVALHO, E. J. G. Estudos comparados em educação: novos enfoques teórico-metodológicos. Acta Scientiarum Education, v. 36, n. 1, p. 129-141, jan./jun. 2014.

COELHO, C. Sujeitos e processos institucionais: práticas avaliativas interativas na UnB no âmbito do SINAES. In: CONFERÊNCIA DO FÓRUM DE GESTÃO DO ENSINO SUPERIOR NOS PAÍSES E REGIÕES DE LÍNGUA PORTUGUESA, 2. 2012, Macau. Anais... Macau, 2012. p. 1-13.

COWEN, R.; KAZAMIAS, A. M.; ULTERHALTER, E. Introdução: o nacional, o internacional e o global. In: COWEN, R.; KAZAMIAS, A. M.; ULTERHALTER, E. (Org.). Educação comparada: panorama internacional e perspectivas. Brasília, DF: Capes/Unesco, 2012a.

COWEN, R.; KAZAMIAS, A. M.; ULTERHALTER, E. (Org.). Educação comparada: panorama internacional e perspectivas. Brasília, DF: Capes/Unesco, 2012b. v. 1.

DALE, R. Globalização e Educação: Demonstrando a existência de uma “cultura educacional mundial comum" ou localizando uma "agenda globalmente estruturada para a educação"? Revista Educação \& Sociedade, São Paulo: Cortez, v. 25, n. 87, p. 423-460, maio/ago. 2004.

DIAS SOBRINHO, J. Avaliação da educação superior: conflitos e paradigmas. In: CONFERÊNCIA DO FÓRUM DE GESTÃO DO ENSINO SUPERIOR NOS PAÍSES E REGIÕES DE LÍNGUA PORTUGUESA, 2., 2012, Macau. Anais... Macau, 2012. p. 1-14. 
DIAS SOBRINHO, J. Avaliação e transformações da educação superior brasileira (1995-2009): do PROVÃO ao SINAES. Avaliação, Campinas, v. 15, n. 1, p. $195-$ 224, mar. 2010.

FERRÃO, J. Palavras de abertura do Presidente da Associação das Universidades de Língua Portuguesa (AULP) e Magnífico Reitor da Universidade de Lúrio. In: ENCONTRO DA AULP, 23., 2013, Belo Horizonte. Anais... Belo Horizonte, 2013.

FERREIRA, M. M.; MOREIRA, R. L. Capes, 50 anos: depoimentos ao CPDOC/ FGV. Brasília, DF: Capes, 2002.

GRAÇA, C. Gestão da educação superior: inclusão, dialéctica, extensão, avaliação e monitoria da qualidade do ensino. In: CONFERÊNCIA DO FÓRUM DE GESTÃO DO ENSINO SUPERIOR NOS PAÍSES E REGIÕES DE LÍNGUA PORTUGUESA, 2., 2012, Macau. Anais... Macau, 2012. p. 1-10.

LAW, W. O estado desenvolvimentista, mudança social e educação. In: COWEN, R.; KAZAMIAS, A. M.; ULTERHALTER, E. (Org.). Educação comparada: panorama internacional e perspectivas. Brasília, DF: Capes/Unesco, 2012. v. 1.

MALET, R. Do Estado-Nação ao Espaço-Mundo: as condições históricas da renovação da educação comparada. Educação e Sociedade, v. 25, n. 89, p. 1301-1332, 2004.

MENDES, M.; SILVA, E. Avaliação, Acreditação e Gestão do Ensino Superior em Angola: percepções, desafios e tendências. In: CONFERÊNCIA DO FÓRUM DE GESTÃO DO ENSINO SUPERIOR NOS PAÍSES E REGIÕES DE LÍNGUA PORTUGUESA, 1., 2011, Lisboa. Anais... Lisboa, 2011. p. 1-14.

MENDONÇA, J. et al. Qualidade do Ensino Superior no Brasil: uma análise do instrumento formal de avaliação. In: CONFERÊNCIA DO FÓRUM DE GESTÃO DO ENSINO SUPERIOR NOS PAÍSES E REGIÕES DE LÍNGUA PORTUGUESA, 2. 2012, Macau. Anais... Macau, 2012. p. 1-14.

MOROSINI, M. C. Estado do conhecimento sobre internacionalização da educação superior - Conceitos e práticas. Educar, Curitiba, n. 28, p. 107-124, 2006.

MOROSINI, M. C.; FRANCO, M. E. P. Educação superior brasileira: encruzilhada na questão da qualidade. In: MACIEL, A. M. R. et al. (Org.). Universidade hoje: o que precisa ser dito? Santa Maria: Ed. UFSM, 2012.

NEAVE, G. O Estado-avaliador como política em transição: um estudo histórico e anatômico. In: COWEN, R.; KAZAMIAS, A. M.; ULTERHALTER, E. (Org.)

Educação comparada: panorama internacional e perspectivas. Brasília, DF: Capes/ Unesco, 2012. 
PEIXOTO, M. C. L. Avaliação institucional externa no SINAES: considerações sobre a prática recente. Avaliação, Campinas, v. 16, n. 1, p. 11-36, mar. 2011.

POPKEWITZ, T. Algunos problemas y problemáticas en la producción de la evaluación, Revista de Educación, $\mathrm{n}^{\circ}$ 229. Madrid: Centro de Publicaciones del Ministerio de Educación y Ciencia, 1992. p. 95 -118.

RODRIGUES, I.; MACHADO, M.; ARAÚJO, J. Expansão do Ensino Superior no Brasil: avaliação como mecanismo para a garantia da qualidade. In: CONFERÊNCIA DO FÓRUM DE GESTÃO DO ENSINO SUPERIOR NOS PAÍSES E REGIÕES DE LÍNGUA PORTUGUESA, 1., 2011, Lisboa. Anais... Lisboa, 2011. p. 1-11.

SCHNEIDER, M. P.; ROSTIROLA, C. R. Estado-Avaliador: reflexões sobre sua evolução no Brasil. RBPAE, v. 31, n. 3, p. 493-510, set./dez. 2015.

SCHRIEWER, J. Sistema Mundial e Inter-Relacionamento de Redes: a Internacionalização da Educação e o Papel da Pesquisa Comparativa. Revista Brasileira de Estudos Pedagógicos, Brasília, DF, v. 76, n. 182-183, p. 241-304, jan./ago. 1995.

TAUCHEN, G.; MENDES, M. C. B. R.; DEVECHI, C. P. V. Garantia da qualidade e da avaliação: um estudo comparado sobre as decorrências do processo de Bolonha na comunidade dos países de língua portuguesa. Espaço Pedagógico, v. 22, p. 240 $263,2015$.

TEODORO, A.; ANÍBAL, G. A educação em tempos de globalização: modernização e hibridismo nas políticas educativas em Portugal. Revista Iberoamericana de Educación, n. 48, p. 73-91, 2008.

TEODORO, A.; ANÍBAL, G. A educação em tempos de globalização neoliberal. Os novos modos de regulação das políticas educacionais. Brasília, DF: Liber Livro, 2011.

TEODORO, A.; ANÍBAL, G. Educação Superior e inclusão, tendências e desafios no século XXI. Temas em Educação, João Pessoa, v. 22, n. 2, p. 225-238, jul./dez. 2013.

UNESCO. Conferência Mundial sobre Ensino Superior: As Novas Dinâmicas do Ensino Superior e Pesquisas para a Mudança e o Desenvolvimento Social. Paris, jul. 2009.

UNESCO. Declaração Mundial sobre Educação Superior no Século XXI: Visão e Ação. Paris, 09 out. 1998. Disponível em: < http://www.direitoshumanos.usp.br/index.php/Direito-a-Educa\%C3\%A7\%C3\%A3o/declaracao-mundial-sobre-educacao-superior-no-seculo-xxi-visao-e-acao.html>. Acesso em: 02 jan. 2013. 
VARELA, B. L. Importância da avaliação das instituições e cursos do ensino superior em Cabo Verde. In: Ministério do Ensino Superior e Ciência (Org.). Seminário sobre avaliação das instituições do Ensino Superior Cabo-Verdianas. Universidade de Cabo Verde, Cabo Verde, fev. 2013.

VERHINE, R. E.; FREITAS, A. A. S. M. A avaliação da educação superior: modalidades e tendências no cenário internacional. Revista Ensino Superior Unicamp, 2012. Disponível em: $<$ https://www.revistaensinosuperior.gr.unicamp.br/artigos/a-avaliacao-da-educacao-superior-modalidades-e-tendencias-no-cenario-internacional>. Acesso em: 05 jan. 2015.

Recebido em: 09 de agosto de 2016 Aceito em: 28 de novembro de 2016

Endereço para correspondência: Campus Universitário Darcy Ribeiro, 70910-900, Brasília, Distrito Federal, Brasil; devechi@unb.br 